\title{
Violência contra a mulher e a lei Maria da Penha: desafios na sociedade patriarcal-racista-capitalista do Estado brasileiro
}

\author{
Violence against women and the Maria da Penha law: challenges in \\ the patriarchal-racist-capitalist society of the Brazilian State
}

\section{Mirla Cisne* Giulia Maria Jenelle Cavalcante de Oliveira**}

\begin{abstract}
Resumo
O objetivo deste artigo é analisar o fenômeno da violência contra a mulher em uma sociedade patriarcal-racista-capitalista, particularmente, no Brasil. Como objetivos específicos, pretendeu-se: tecer reflexões analíticas sobre a Lei Maria da Penha, considerada o principal marco legal de conquista das mulheres frente à violência; apontar desafios para a efetivação dessa lei e para a construção de uma vida sem violência. Para corresponder a esses objetivos, desenvolveu-se uma pesquisa bibliográfica e documental, de natureza, fundamentalmente, qualitativa, ainda que a dimensão quantitativa esteja aqui presente, na manifestação de dados sobre violência contra a mulher no Brasil. As principais conclusões é de que a violência contra a mulher não se restringe às relações pessoais, familiares, mas, está presente nas diversas relações sociais de sexo, raça e classe que combinadas dialeticamente, exploram, oprimem e submetem às mulheres a múltiplas situações de desigualdade em relação aos homens; a Lei Maria da Penha é a principal e mais avançada legislação brasileira e trouxe diversos avanços normativos, todavia, sua efetividade encontra limites objetivos em um Estado patriarcal-racista-capitalista, fomentador de múltiplas violências.
\end{abstract}

Palavras-Chave: Patriarcado. Violência contra mulher. Lei Maria da Penha.

\begin{abstract}
The objective of this article is to analyze the phenomenon of violence against women in a patriarchalracist-capitalist society, particularly in Brazil. As specific objectives, we intend to make analytical reflections on the Maria da Penha Law, considered the main legal framework for women's conquest of violence; and to point out challenges for the implementation of this law and for the construction of a life without violence. In order to acomplish these objectives, we have developed a bibliographical and documentary research of a fundamentally qualitative nature, even though the quantitative dimension is present in the manifestation of data on violence against women in Brazil. Our main conclusions are that violence against women is not restricted to personal relationships, but it is present in the whole social relations of sex, race and class that combine dialectically, exploit, oppress and subject women to multiple situations of inequality in relation to men; the Maria da Penha Law is the main and most advanced Brazilian legislation and has brought several normative advances, nevertheless, its effectiveness finds objective limits in a patriarchal-racist-capitalist State that foments multiple violence.
\end{abstract}

Keywords: Patriarchy. Violence against women. Maria da Penha Law.

\footnotetext{
* Doutora em Serviço Social pela Universidade do Estado do Rio de Janeiro (UERJ), Profa. Adjunta da Universidade do Estado do Rio Grande do Norte (UERN), Líder do Grupo de Estudo sobre as relações sociais de gênero e feminismo (GEF); membro do Núcleo de Estudos sobre a Mulher Simone de Beauvoir. E-mail: mirlacisne@gmail.com

** Advogada, integrante do Grupo de Estudos em Direito Crítico, Marxismo e América Latina (GEDIC) da Universidade Federal do Semiárido (UFERSA). E-mail: giuliamjco@gmail.com
} 


\section{Introdução}

"Todas as manhãs ela deixa os sonhos na cama, acorda e põe sua roupa de viver"

Clarice Lispector

É muito comum associar a violência contra a mulher (VCM) ao âmbito doméstico, o que não é incorreto, já que é um espaço onde ela se manifesta comum e fortemente. Entende-se, todavia, que a VCM está presente em todo o tecido social, de uma sociedade estruturalmente patriarcal-racista-capitalista. Em outras palavras, o que ocorre em âmbito doméstico é, em grande medida, resultado das relações sociais antagônicas de sexo, raça e classe.

Nesse sentido, entende-se que a VCM não é restrita às relações individuais, familiares, ainda que seja uma intensa marca de tais relações. O patriarcado, como sistema de opressão e exploração sobre as mulheres, forja relações estruturantes de violência contra as mesmas e violação de seus direitos. Como mulheres, têm seus corpos apropriados e explorados, a serviço dos outros, inclusive, sexualmente. Assim, além da exploração direta sobre o trabalho assalariado, estão submetidas às relações que prolongam a servidão e a escravidão em nossas vidas, constituindo a sexagem, ou seja, o processo de coisificação das mulheres. Em outras palavras, a sexagem diz respeito à apropriação material concreta da individualidade corporal das mulheres, em um processo que as tira da condição de sujeito e as tornam "coisas" (GUILLAUMIN, 2014). Ainda segundo Collete Guillaumin, os homens "possuem as mulheres e as 'gerenciam' de fato como uma possessão material, na reprodução" (GUILLAUMIN, 1994). Sob a concepção patriarcal, a mulher "nasce para ser mãe" e cuidar do lar, sendo submetida às opressões e desigualdades, como uma condição de "impotência" em relação ao poder dos homens.

É preciso, porém, chamar a atenção para o seguinte: a impotência, sem dúvida, constitui fonte de violência; mas usa expressão, ou melhor, a manifestação violenta da impotência, encontra limites sociais variáveis segundo a categoria social à qual pertence o socius. Para os homens brancos e ricos, os limites são extremamente lassos. À medida que se desce na escada de poder da sociedade, os limites se vão estreitando para atingir um elevado grau de rigidez na vida da mulher. Deixando-se de lado as crianças e os velhos (estes quando dependentes física, psíquica ou economicamente), as mulheres ocupam o último posto da hierarquia de poder (SAFFIOTI, 1995, p. 43). 
Como não caracterizar esse processo como expressão de violência? A violência que ocorre em âmbito doméstico/familiar, resulta dessas relações de sexagem, estruturantes do patriarcado. Por sua vez, o patriarcado encontra na divisão sexual do trabalho, seu fundamento material, catalizadora do objetivo maior do capital: a obtenção de superlucros. Em nome dos lucros, submetem os/as trabalhadores(as) à condição de mercadoria, de coisa, mais fortemente as mulheres e dentre essas, as negras. Quanto mais desvalorizada, coisificada, apropriada e não remunerada à força de trabalho, mais se possibilita a agudização da exploração, fundamento das divisões da humanidade em sexos, raças e classes.

Entende-se, assim, que as relações sociais de sexo $^{1}$, raça e classe são determinantes das múltiplas expressões de desigualdades e violências. Isso não significa dizer que as relações individuais homens $x$ mulheres não imprimam mediações que também implicam na VCM, todavia, a relação desigual de poder entre esses sujeitos advém das relações patriarcais.

O objetivo deste artigo é analisar o fenômeno da violência contra a mulher em uma sociedade patriarcal-racista-capitalista, particularmente, no Brasil. Como objetivos específicos, pretende-se: tecer reflexões analíticas sobre a Lei Maria da Penha, considerada o principal marco legal de conquista das mulheres frente à violência; apontar desafios para a efetivação dessa lei e para a construção de uma vida sem violência.

Para corresponder a esses objetivos, desenvolveu-se uma pesquisa bibliográfica e documental, de natureza, fundamentalmente, qualitativa, ainda que a dimensão quantitativa esteja aqui presente, na manifestação de dados sobre violência contra a mulher no Brasil.

Ao ampliar a compreensão de violência para além do âmbito domésticofamiliar, buscou-se contribuir com a denúncia ao modelo de sociedade vigente. Uma sociedade em que a violência não é apenas produzida, como é, também, naturalizada, banalizada, especialmente sobre as mulheres pobres e negras. Assim, apontou-se aqui,

\footnotetext{
1 "Relações sociais de sexo" é uma categoria de origem francófona. Na língua de origem, é denominada rapports sociaux de sexe e não relations sociaux de sexe. Como não se tem uma tradução no português para rapports, traduziu-se para relações, que seria a tradução fiel de relations e não de rapports. Contudo, o sentido que gostar-se-ia de dar é o de rapports, por estar vinculada às relações sociais mais amplas e estruturantes, diferente de relations que, no francês, designa-se às relações individuais. Para um maior aprofundamento, ver Cisne (2014).
} 
que a luta contra a violência à mulher é também uma luta contra o sistema patriarcalracista-capitalista.

\section{Violência Contra a Mulher em uma Sociedade Patriarcal-Racista-Capitalista}

Compreende-se a violência contra a mulher como uma violação sistemática de direitos, que fere e afeta não apenas a integridade física, mas, também social, emocional e subjetiva. Para Alemany (2009, p. 271), a violência contra a mulher consiste em:

[...] todos os atos que, por meio de ameaça, coação ou força, lhes infligem, na vida privada ou pública, sofrimentos físicos, sexuais ou psicológicos com finalidade de intimidá-las, puni-las, humilhá-las, atingi-las na sua integridade física e na sua subjetividade.

Nesse sentido, é um ato coercitivo perpetrado contra as mulheres, independentemente do meio onde ocorre ou de quem comete (BARROSO, 2015). Essa violência não se limita, portanto, ao ambiente doméstico, embora seja um lugar comum de ocorrê-la, sendo geralmente praticada pelo cônjuge ou ex-cônjuge, pelo pai e irmãos. O lugar supostamente idealizado como de afeto, amor, proteção e acolhimento, torna-se, muitas vezes, lócus da violência.

Embora comumente identifique-se a VCM em suas múltiplas expressões (física, psicológica, moral, patrimonial, sexual, etc.) como algo decorrente de uma relação conjugal homem $x$ mulher, entende-se que esse fenômeno atinge não apenas as mulheres em suas relações individuais. A VCM atinge as mulheres em seu conjunto, como categoria de sexo, devido às relações sociais patriarcais que perpassam antagonismos, hierarquias, explorações e apropriações, dos homens, coletivamente e individualmente, sobre as mulheres. Essas relações patriarcais (ou relações sociais de sexo), por sua vez, estão imbricadas dialeticamente com as relações sociais de raça e classe, fundando o "nó" que compõe o sistema "patriarcal-racista-capitalista" (SAFFIOTI, 2004) que estrutura a sociedade brasileira, desigual e autoritária. Para Chauí (2007, p. 90), essa sociedade é: 
[...] estruturada pela matriz senhorial da Colônia [...]. As divisões são naturalizadas em desigualdades postas como inferioridade natural (no caso das mulheres, dos trabalhadores, negros, índios, imigrantes, migrantes e idosos). [...] Essa naturalização, que esvazia a gênese histórica da desigualdade e da diferença, permite a naturalização de todas as formas visíveis e invisíveis de violência, pois estas não são percebidas como tais.

Nesse sentido, em conjunto, as relações sociais de sexo, raça e classe atuam nas determinações das violências contra as mulheres e ao se associarem às ideologias dominantes (patriarcal, racista e elitista), naturalizam as desigualdades, as opressões e explorações de forma a não serem percebidas como tais.

Por entender que a violência contra a mulher de forma estruturante, considera-se que as denominações: violência doméstica, familiar, intrafamiliar e conjugal, não contemplam à caracterização da violência sexista nesta sociedade patriarcal. Da mesma forma, considerou-se que violência de gênero não explicita a condição específica da mulher como sujeito central de violações advindas em uma sociedade patriarcal. Considerou-se indispensável dar visibilidade aos sujeitos que estabelecem às relações de antagonismo e conflitos nas relações patriarcais, no caso, centralmente, homem $x$ mulher. Violência de gênero não necessariamente é contra uma mulher. Referir-se à violência de gênero como sinônimo de violência contra a mulher é cair na armadilha da ocultação dos sujeitos, o que politicamente é uma perda em termos de denúncia e organização feminista. Daí a opção teórico-política pela denominação violência contra a mulher.

A violência contra a mulher extrapola as relações conjugais e o âmbito doméstico. Por isso, conforme aponta Milena Barroso (2015), cabe atentar-se à totalidade da questão e ampliar a análise para além da abrangência doméstica do fenômeno, na tentativa de não fragmentar ou dissociar às manifestações de violências estruturais e às violências interpessoais. Afinal, são múltiplas as manifestações e situações de violência contra as mulheres. Como diz Bandeira (2009, p. 8):

A categoria "violência contra a mulher" embora revestida de complexidade conceitual, além de ser polissêmica e multicausal, é tomada como um instrumento de controle viril sobre os corpos femininos, que abriga um repertório de práticas diversas em intensidade e extensão.

Pode ser entendido como: a violência contra mulher como todo ato que expresse esse controle vil sobre nossos corpos, seja fisicamente ou simbolicamente. 
Entende-se que os processos de exploração e apropriação sobre as mulheres, resultantes de relações patriarcais, convergem com o racismo de forma a intensificar expressões de violências sociais contra a mulher, ao construir desigualdades em relação aos homens, vulnerabilizando-as, especialmente as negras, às piores condições de vida e trabalho.

Essa condição de desigualdade, envolta em exploração e opressões, constitui também relações desiguais de poder e intensifica a coisificação (relações de sexagem) sobre as mulheres. Para nós, são essas relações de sexagem que estruturam às múltiplas formas de violência contra a mulher.

Quando foi ressaltado que as mulheres pobres e negras são mais vulneráveis à violência e violação de direitos, não negou-se que as mulheres brancas e ricas também sofrem violência. Todas as mulheres numa sociedade patriarcal, sofrem, de alguma forma, violência. As relação de classe e raça, todavia, complexificam às violências sexistas, pois imprimem determinações estruturantes de desigualdades. Em outras palavras, o que se quer afirmar é que a VCM é também mediada pelas relações de classe e pelo racismo que estruturam historicamente a sociedade brasileira, juntamente com o patriarcado. Esse pensamento se assenta na compreensão já apontada, de que a violência não se restringe às relações individuais, mas corresponde a tudo que nega a condição humana, que explora, oprime e viola as condições de integridade do nosso corpo e espírito.

Para exemplificar reflexos de violações históricas, serão apontados dados e reflexões para a percepção da persistência do patriarcado na sociedade brasileira, imbricado às relações de classe e raça. Segundo o IBGE $(2010)^{2}$, em 2010, 33,7\% das mulheres e $25,7 \%$ dos homens tinham rendimento mensal de até 1 salário mínimo. Dentre as mulheres negras 40,3\% recebiam até 1 salário mínimo, já as camponesas, recebiam 50,5\%. As mulheres permanecem, ainda, com rendimento médio inferior ao dos homens, o equivalente a $67,7 \%$. Comparando o rendimento médio das mulheres negras com o rendimento médio dos homens brancos, têm-se o equivalente a $35 \%$, o que demostra a desigualdade abissal quando considera-se a combinação das variáveis

\footnotetext{
2 Trata-se do livro: "Estatísticas de gênero: uma análise dos resultados do censo demográfico de 2010". Disponível em: http://biblioteca.ibge.gov.br/pt/biblioteca-catalogo?view=detalhes\&id=288941. Acessado em 15 de junho de 2017.
} 
sexo e raça. O rendimento médio das mulheres negras em relação ao das brancas, foi equivalente a 52\%. Já as mulheres brancas em relação ao rendimento dos homens brancos, obteve o equivalente de $67 \%$. As mulheres camponesas ${ }^{3}$ possuem a menor renda registrada (480,00 reais), valor abaixo do salário mínimo em 2010. Em relação à ausência de renda, registrou-se que $30,4 \%$ das mulheres com 16 anos ou mais não tinha nenhum rendimento em comparação a 19,4\% dos homens (IBGE, 2010).

No campo da política, de acordo com o Cfemea (2014), as mulheres representaram $51,9 \%$ dos eleitores, mas somente $13,4 \%$ de vereadores, $11 \%$ dos prefeitos, $14,8 \%$ dos senadores, $7,4 \%$ dos governadores, $8,7 \%$ dos deputados federais e $12,8 \%$ dos estaduais.

No Brasil, a VCM atinge índices alarmantes. Entre 2001 e 2011, estima-se que ocorreram mais de 50 mil assassinatos de mulheres pela sua condição de sexo, ou seja, são cerca de 5.000 mortes por ano (GARCIA et al., [s/d] [s/p]). Esses índices denunciam a grave existência do feminicídio em no País.

Dados da Central de Atendimento à Mulher ${ }^{4}$ mostram que o tipo de registro mais recorrente é de violência física, seja ela enquadrada como lesões leves, graves e lesões gravíssimas, chegando a ocorrências de tentativa de homicídio e homicídio consumado. A violência psicológica está em segundo lugar, seguida pela violência moral, patrimonial, sexual e outros tipos de violência.

Identificou-se, portanto, por meio desses dados, que a violência contra a mulher se expressa não apenas quando a mulher é vítima de espancamentos, por exemplo, mas em tudo que revela a sua inferiorização, exploração, desigualdade e subordinação em relação aos homens pela sua condição de sexo social, complexificada pela condição étnico-racial e de classe que marcam a violência perpetrada em um Estado estruturalmente patriarcal.

\footnotetext{
${ }^{3}$ O IBGE utiliza a terminologia mulher rural, todavia, optou-se por adotar a expressão camponesa por corresponder não apenas a uma dimensão físico-geográfica, mas, sobretudo de identidade política.

${ }^{4}$ Dados retirados da Secretaria de Políticas para as Mulheres, Central de Atendimento à Mulher (ligue 180). Disponível em https://teen.ibge.gov.br/noticias-teen/2822-violencia-contra-mulher. Acessado em 25 de setembro de 2017.
} 


\title{
A violência e a vitimização secundária: desvelando a face patriarcal do Estado
}

Apesar dos dados aqui elencados, é importante ressaltar que o fenômeno da violência não se restringe a uma classe ou raça, ainda que esses determinantes o agudizem e o particularizem:

\begin{abstract}
O fenômeno desconhece qualquer fronteira: de classes sociais, de tipo de cultura, de grau de desenvolvimento econômico, podendo ocorrer em qualquer lugar - no espaço público como no privado - e ser praticado em qualquer etapa da vida das mulheres e por parte de estranhos ou parentes/conhecidos, especialmente destes últimos (SAFFIOTI, 1995, p. 8).
\end{abstract}

A violência é marca presente na vida das mulheres no mundo inteiro e no Brasil. O Estado é o terceiro nessa relação triangular, na qual têm-se o violentador, a violentada e o Estado que possui como poder-dever, substituir a vítima nessa relação, "guardião" e defensor dos direitos humanos. No entanto, fica o questionamento: como substituir uma vítima, sendo um "estranho" à relação? Utilizando-se apenas de técnicas normativas? Sem ter sentido as dores e perturbações sofridas pela vítima?

É percebido que a vítima sofre um processo de privação da sua identidade, torna-se um número de processo penal, suas expectativas são deixadas de lado, suas necessidades não são levadas em consideração. Oliveira (1999, p. 109), afirma que:

No sistema penal atual, os conflitos são decididos por pessoas estranhas e as partes originalmente envolvidas desaparecem. Aquela que é representada pelo Estado - a vítima - só tem papel de desencadear o processo e prestar algumas informações. A vítima é uma perdedora diante do autor da infração e diante do Estado; não recupera o que perdeu para o infrator, pois as penas não levam em conta seus interesses, e perde ainda a oportunidade de vivenciar de forma positiva o conflito, que não é mais seu. A localização das salas de julgamento nos tribunais das cidades grandes, a ritualização dos atos, a linguagem peculiar - uma verdadeira subcultura -, tudo afasta a vítima que, quando comparece em juízo, percebe que seu conflito é propriedade dos advogados, dos promotores, dos juízes. A despersonalização dos conflitos reflete o desempenho dos papéis sociais; nas sociedades industrializadas, as pessoas se conhecem em fragmentos, de acordo com os papéis que desempenham em cada cenário da vida, e o sistema penal não oferece oportunidade para que as partes e os operadores atuem como seres humanos integrais.

Essa falta de atenção do processo penal para com a vítima (o abandono) causa o fenômeno conhecido como "sobrevitimização" ou "vitimização secundária" que é o dano adicional causado à vítima de crime ocasionado pela própria mecânica da justiça penal formal. Em uma sociedade capitalista, as pessoas não vêem umas às outras, 
vêem apenas os fragmentos trazidos aos seus olhos e sua percepção, sob o manto de ideologias dominantes, não há a preocupação em perceber nem sentir mais do que está na aparência. É por agir sem empatia, de forma técnica e mecanicista, que o fenômeno da vitimização secundária se firma. Não basta a LMP prevê atendimentos personalizados às mulheres em situação de violência se esse processo não for humanizado e não vitimizador. Como ainda revela Oliveira (1999, p. 113):

\begin{abstract}
Vale analisar alguns possíveis motivos pelos quais a vitimização secundária é mais preocupante que a primária. O primeiro deles diz respeito ao desvio de finalidade: afinal, as instâncias formais de controle social destinam-se a evitar a vitimização. Assim, a vitimização secundária pode trazer uma sensação de desamparo e frustração maior que a vitimização primária (do delinquente [sic], a vítima não esperava ajuda ou empatia). Assim, temos o acusado (vitimização primária) e o aparelho de repressão policial/judicial estatal vitimizador (vitimização secundária).
\end{abstract}

O Estado assim, trazido pelo direito pátrio como terceiro garantidor dos Direitos Humanos (em um Estado Moderno e "democrático" de direito), terceiro em uma relação triangular, chamado à causa para resolução do conflito, é também, paradoxalmente, fomentador de violência, por meio de diversas situações sociais:

\footnotetext{
Falar do Estado, em tal âmbito, implica rever sua posição de garante dos Direitos Humanos; e de seu lugar no Estado Moderno, da sua crise diante da falta de teoria e sustentá-lo ou tão só do cumprimento efetivo - ou não das suas incumbências; assim como de seu papel de fomentador da violência e, portanto, do agravamento do rol de vítimas [...] Afinal, de um lado tem-se clara vendeta, lançada em nome seja lá do que for, de Deus (ou deus?) à razão, ou o mercado, nos dias atuais; de outro, uma retórica de proteção em nome da cidadania [...] (COUTINHO, 2010, p. 480).
}

Diante desse Estado fomentador da violência, as mulheres, são as mais vitimizadas, devido às condições históricas de uma sociedade patriarcal, gerando formas de discriminações e práticas sociais que permitem o ataque a sua integridade, saúde, desenvolvimento, vida, autonomia e liberdade.

\title{
Conquistas Legais x Direitos Reais: um Breve Balanço da Lei Maria da Penha
}

A luta pelo direito das mulheres a uma vida sem violência começa a ganhar força apenas a partir da década de 1970. Resultado da luta do movimento feminista, a partir desse período, diversos tratados foram aprovados no processo de internacionalização dos direitos humanos. 
Durante o Pós-Segunda Guerra Mundial, ocorre um crescente movimento em defesa dos Direitos Humanos, pós-holocausto. O princípio da dignidade humana agora dá base de sustentação à luta por diversos direitos, influenciando, também, a luta pelos direitos das mulheres. Ficou definido 1975, como o Ano Internacional da Mulher, pela Organização das Nações Unidas (ONU). A partir desse momento, iniciam-se uma série de debates e eventos sobre os direitos femininos.

O primeiro tratado que dispõe de forma ampla sobre os direitos das mulheres foi em 1979, com a Convenção sobre Eliminação de Todas as Formas de Discriminação contra a Mulher. O seu objetivo foi promover os direitos na incessante busca de igualdade, bem como prevenir quaisquer tipos de discriminações. Esta Convenção deve ser tomada como parâmetro mínimo das ações estatais, estabelecendo medidas para alcançar a igualdade entre homens e mulheres cabendo ao final, aos Estadospartes adotarem essas medidas. Não é, porém, a simples enunciação formal que irá salvaguardar esses direitos. É preciso que os poderes Legislativo, Executivo e Judiciário cumpram os seus papéis constitucionalmente previstos e pratiquem ações tendo por intuito elaborar medidas legislativas, administrativas, assim como medidas temporárias como as ações afirmativas, que modifiquem os padrões econômicos, sociais e culturais.

Em 1993, a Conferência Mundial dos Direitos Humanos, reconhece que a promoção e proteção dos direitos humanos das mulheres devem ser prioritárias para toda a comunidade internacional. É somente em 1994, com a Organização dos Estados Americanos, que a Declaração sobre a Eliminação da Violência contra a Mulher ganha força de lei. Surge então, o conceito de violência contra a mulher no Brasil, sendo entendida como "[...] qualquer ação ou conduta baseada no gênero, que cause morte, dano ou sofrimento físico, sexual ou psicológico à mulher, tanto no âmbito público como no privado"5.

No Brasil os direitos das mulheres foram sendo conquistados com vagar. Foi somente em 1962, com o Estatuto da mulher casada, que após 462 anos a mulher deixou de ser considerada relativamente incapaz. Veio então a Lei do Divórcio (Lei 6.515/77) que trouxe ínfimos avanços, tornando facultativa a adoção de nome do cônjuge, bem como estendeu ao marido o direito de pedir alimentos. Apenas com a

\footnotetext{
${ }^{5}$ Brasil. Decreto $n^{\circ} 1.973$ de $1^{\circ}$ de Agosto de 1996. Brasília.
} 
constituição de 1998, a mulher consegue consumar no campo formal, a igualdade de direitos e deveres na família (LÔBO, 2003).

A Constituição Federal Brasileira de 1988 em seus art.3 IV, e 5 estabelece o direito à igualdade, tendo como objetivo fundamental do Estado promover o bem de todos, sem preconceito de sexo, assim como a igualdade de todos perante a lei. É com base nessa igualdade material, que a Lei Maria da Penha ganha força, sendo promulgada e declarada constitucional.

Diante de um quadro de violência contra as mulheres, sendo recorrentemente assassinadas e violentadas em âmbito doméstico, que organizações feministas promovem a conquista da aprovação da Lei Maria da Penha (LMP) em 2006. Essa lei foi assim nomeada em decorrência do caso de Maria da Penha Fernandes ${ }^{6}$ que levou sua luta por justiça à Organização dos Estados Americanos (OEA), tornando-se um símbolo contra a impunidade. A importância dessa lei em termos de conquista legal, demanda algumas reflexões mais consistentes sobre as mudanças que promoveu e vem promovendo.

Antes da LMP não havia nenhuma lei específica para os casos de violência contra as mulheres. Os casos, geralmente, eram julgados pela Lei 9.099/95, que trata de "crimes de menor potencial ofensivo", sendo equiparados aos casos de briga entre vizinhos e de acidente de trânsito. Os homens agressores só eram presos em caso de homicídio ou lesão corporal grave que impossibilitasse a vítima de trabalhar por mais de 30 dias. Nesses casos, a violência era julgada pelo código penal.

A LMP, resultado de uma longa trajetória de luta dos movimentos feministas e dos direitos humanos, passa a reconhecer e tratar a violência contra a mulher como uma questão pública e, como tal, como dever do Estado em intervir e coibir sua prática. Para tanto, a LMP:

[...] cria mecanismos para coibir e prevenir a violência doméstica e familiar contra a mulher, nos termos do $\S$ 8o do art. 226 da Constituição Federal ${ }^{7}$, da Convenção sobre a Eliminação de Todas as Formas de Violência contra a Mulher, da Convenção Interamericana para Prevenir, Punir e Erradicar a

\footnotetext{
${ }^{6}$ Maria da Penha levou um tiro do seu marido enquanto dormia no ano de 1983, ficando paraplégica. Após o retorno para casa do hospital, o mesmo tentou eletrocutá-la. O réu somente foi condenado em 2002, decorrendo então apenas dois de prisão.

${ }^{7} \S 8^{\circ}$ - O Estado assegurará a assistência à família na pessoa de cada um dos que a integram, criando mecanismos para coibir a violência no âmbito de suas relações.
} 
Violência contra a Mulher e de outros tratados internacionais ratificados pela República Federativa do Brasil; dispõe sobre a criação dos Juizados de Violência Doméstica e Familiar contra a Mulher; e estabelece medidas de assistência e proteção às mulheres em situação de violência doméstica e familiar $\left(\operatorname{art} .1^{\circ}\right)$.

No seu artigo $5^{\circ}$, a LMP dispõe sobre o entendimento de violência contra a mulher:

Art. $5^{\circ}$ Para os efeitos desta Lei, configura violência doméstica e familiar contra a mulher qualquer ação ou omissão baseada no gênero que lhe cause morte, lesão, sofrimento físico, sexual ou psicológico e dano moral ou patrimonial:

I - no âmbito da unidade doméstica, compreendida como o espaço de convívio permanente de pessoas, com ou sem vínculo familiar, inclusive as esporadicamente agregadas;

II - no âmbito da família, compreendida como a comunidade formada por indivíduos que são ou se consideram aparentados, unidos por laços naturais, por afinidade ou por vontade expressa;

III - em qualquer relação íntima de afeto, na qual o agressor conviva ou tenha convivido com a ofendida, independentemente de coabitação.

Parágrafo único. As relações pessoais enunciadas neste artigo independem de orientação sexual (destaque nosso).

Como percebe-se, a concepção de violência contra a mulher por parte da LMP é ampla, incluindo, a violência psicológica. Considera-se isso um grande avanço, posto que a VCM, comumente, era restrita a violência física e, ainda assim, muitas vezes sendo encarada como um problema de ordem privada. Destaca-se, ainda, que a LMP foi a primeira lei brasileira a reconhecer a conjugalidade entre pessoas do mesmo sexo, abrindo, portanto, caminhos legais para a conquista de direitos por parte das pessoas não-heterossexuais que até então, nunca contaram com um aparato jurídicoinstitucional a seu favor.

Além da Lei Maria da Penha, também do ponto de vista normativo, destacouse como uma importante conquista à revisão e reedição da Norma Técnica sobre a Prevenção e Tratamento dos Agravos Resultantes da Violência Sexual contra Mulheres e Adolescentes. A norma data de 1998 e trata da regulamentação do artigo 128, inciso I do Código Penal, que possibilita o aborto legal às mulheres vítimas de estupro. A inovação da revisão consiste em não mais exigir o Boletim de Ocorrência para as vítimas de estupro realizarem o aborto legal. Além disso, passou a estabelecer regras e providências para assistência às mulheres vítimas de violência sexual. Com isso, conquistou-se fomento para a implementação de serviços de saúde especializados 
para o atendimento a essas mulheres. Segundo a AMB (2011, p. 43), "de 2007 para 2010 o número de serviços que prestavam esse tipo de atendimento passou de 138 para 442, sendo que desses 60 realizam atendimento para a realização do aborto previsto em lei".

Essa norma técnica, sem dúvida possibilitou um grande avanço do ponto de vista normativo para as mulheres vítimas de violência sexual possuírem ao menos, o acesso ao aborto seguro no serviço público de saúde, ainda que não garanta sua efetividade.

A LMP, é sem dúvida, a legislação mais abrangente e específica para tratar da VCM. Ao definir a violência contra a mulher como "qualquer ação ou omissão que lhe cause morte, lesão, sofrimento físico, sexual ou psicológico e dano moral ou patrimonial"8, o conceito passa por um amadurecimento que leva em consideração a complexidade que permeia os laços de familiaridade e afetividade. Por outro lado, ao estabelecer uma séria de garantias e proteções à mulher ${ }^{9}$, desafia o Estado a se modernizar para que possa tratar de modo eficiente a violação desses direitos, bem como possuir o dever de captar e monitorar os dados estatísticos para estabelecimentos de posteriores diretrizes ${ }^{10}$.

A positivação de uma determinada lei, por vezes, revela conquistas democráticas, como é o caso da LMP, todavia, apenas com a positivação não se tem a garantia de efetivação de direitos:

Tem-se claro, pois, que a positivação carrega vantagens e é conquistada desde que tenha por fim a concretização dos princípios, desde que instrumentalize a aplicação das conquistas da humanidade, que são criados e renovados e destruídos pela sociedade civil na sua caminhada histórica a busca de vida digna para todos. A humanidade no seu andar, pois, constrói direitos que são erigidos à condição de princípios norteadores, universais. Assim são o direito à vida, à liberdade, à igualdade (CARVALHO, 1998, p.57).

\footnotetext{
${ }^{8}$ Brasil. Lei $\mathrm{n}^{\circ}$ 11.340, de 7 de agosto de 2006. Brasília. Disponível em: http://www.planalto.gov.br/ccivil_03/_ato2004-2006/2006/lei/l11340.htm. Acesso: 25 de setembro de 2017.

9 Exemplos: casa abrigo; delegacias especializadas; núcleos de defensoria pública especializados; serviços de saúde pública especializados; centros especializados da mulher; Juizados de Violência Doméstica e Familiar contra a Mulher.

${ }^{10}$ Art. $8^{\circ}$, II, da LMP
} 
É inconteste o avanço normativo que a LMP trouxe, todavia, os desafios para a sua efetividade são imensos. A AMB (2011, p. 48) apresenta uma síntese da problemática em torno da efetividade da LMP:

\begin{abstract}
Governos estaduais criam, mas não instalam os equipamentos (delegacias, casas abrigos etc). Outras vezes instalam em condições precárias sem pessoal ou sem infraestrutura física necessária. Ou, como ocorre na maioria dos casos, tem debilidades de gestão da rede ou não investem recursos suficiente para a sua manutenção, funcionamento e ampliação. [...]

Um dos problemas identificados em nossas ações de monitoramento foram os entraves do sistema federativo, que obstaculiza muitos procedimentos de transferência de recursos. Outra questão é o despreparo dos recursos humanos e a prática de contratação por serviços temporários, levando a equipes provisórias nos serviços [...].

Se essa situação não invalida a política, positivamente avaliada, com certeza demonstra como o Estado patriarcal e sua máquina burocrática resistem a inovar em políticas que mudem a vida das mulheres (destaque nosso).
\end{abstract}

As garantias e proteções previstas pela LMP são de grande ganho para a diminuição da violência contra a mulher, porém os dados demonstram que as medidas protetivas previstas, não foram ainda implantadas como deveriam. Exemplo dessa realidade são os dados da Secretaria de Políticas para as Mulheres, que elenca quantitativamente a presença das medidas protetivas nos municípios brasileiros, dentre os quais, apenas $70(1,3 \%)^{11}$ possuem Casas Abrigo. Essas Casas abrigos estão em maior número na região sudeste, assim como a maior concentração das Delegacias Especializadas de Atendimento à Mulher (DEAMs) também se encontra na citada região. São 217 na região sudeste, 95 na região sul, 80 na região Nordeste, 67 no Centro-Oeste e 47 na região Norte, de acordo com os dados da Secretaria de Políticas para as Mulheres (SPM), o que não se faz coerente devido às maiores taxas de feminicídios ${ }^{12}$ serem nas regiões Norte e Nordeste ${ }^{13}$.

11 Segundo dados da Secretaria de Políticas para as Mulheres (SPAM). Disponível em: https://sistema3.planalto.gov.br//spmu/atendimento/atendimento_mulher.php?uf=TD. Acesso: 25 de setembro de 2017.

12 O feminicídio foi introduzido pela Lei 13.104 de março de 2015, disposto no art. 121 inciso VI, "contra a mulher por razões da condição de sexo feminino, considerando que há razões de condição de sexo feminino quando o crime envolve violência doméstica e familiar e menosprezo ou discriminação à condição de mulher. Ao enquadrar o feminicídio como uma das qualificadoras do homicídio, passa assim a ser também, um crime hediondo. A lei do feminicídio é um aperfeiçoamento da normal penal que irá nos permitir a produção de estatísticas e políticas de enfrentamento. 
Em relação aos serviços de saúde especializados de atendimento às mulheres em situação de violência, de acordo com dados da SPM, o número de serviços especializados para atendimento dos casos de violência contra a mulher corresponde em 2015, a 252 (1,91\% do total de municípios), um número ainda inexpressivo.

Em Santa Catarina, por exemplo, uma década após a promulgação da Lei Maria da Penha, não há sequer uma delegacia exclusiva para mulheres, precisando relatar seus casos de violência (sofridos em sua grande maioria por homens) para outros homens. Foi assim que aconteceu com uma jovem de 34 anos que já estava pela segunda vez buscando a Delegacia de Proteção à Criança, adolescente, mulher e idoso (Dpcami) de Florianópolis, para relatar agressões sofridas, pronunciando que sentiu-se julgada pelo policial de plantão: "ele questionou se havia a necessidade de registrar o Boletim de Ocorrência por causa daquilo e seu tinha certeza. Parecia que o policial estava do lado do agressor. Eu saí da delegacia pior do que entrei", lamentou a jovem"14.

De acordo com as fontes ${ }^{15}$ básicas de análises dos homicídios no Brasil entre 1980 e 2013, houve crescente avanço nos casos de homicídios de mulheres. Fazendo uma análise anterior à Lei Maria da Penha e posterior à vigência da Lei, dados do Mapa da Violência de 2015, mostram que antes da lei teve um crescimento de 7,6\% ao ano de homicídios de mulheres, já no período de 2006 (quando entra em vigor a LMP) até 2013, houve um crescimento do número de homicídios de 2,6\% ao ano. Porém, quando levou-se em consideração o crescimento das taxas de homicídios de mulheres, verificou-se que em um primeiro momento - entre 2006 e 2007 - houve uma redução de 4,2\% para 3,9\% por 100 mil mulheres, mas rapidamente a violência retomou seu crescimento, ultrapassando o número de 4,2\% (anterior à Lei Maria da Penha) e colocando esse percentual acima de 4,6\%.

Quando foi levado em consideração os dados de homicídios de mulheres em nível regional, nos Estados do Nordeste houve um crescimento de 79,3\% e na região Norte, esse crescimento foi de 53,7\%. Já no Sul, Centro-Oeste e Sudeste verificou-se

\footnotetext{
13 De acordo com o Mapa da Violência 2015 - Homicídios de Mulheres no Brasil. Julio Jacobo Waiselisz. 1 edição, Brasília-DF, 2015.

${ }^{14}$ Notícia retirada do Diário Catarinense de 28 de outubro de 2017.

${ }^{15}$ Sistema de Informações de Mortalidade (SIM), Secretaria de Vigilância em Saúde (SVS) e do Ministério da Saúde (MS).
} 
um baixo crescimento. É então nas regiões onde o desenvolvimento econômico chegou tardiamente que se vê os maiores índices de feminicídios do País.

Um desenvolvimento econômico tardio, acompanhado de uma sociedade marcada pelo patriarcado, levou a uma inserção também tardia da mulher no mercado de trabalho no Brasil, renegando-a uma condição de submissão e desigualdade social frente ao homem.

As relações étnico-raciais também impactam diretamente na perpetração da violência. De acordo com dados do Mapa da Violência 2015, as mulheres das regiões economicamente mais atrasadas sofrem mais com essa violência - com poucas exceções geográficas -, e a população negra é vítima prioritária da violência homicida no País.

Assim, a VCM está enraizada em relações de desigualdades econômicas e sociais que imprimem desafios concretos para que uma vida sem violência seja um direito garantido a todas as mulheres. Por isso, a Lei Maria da Penha:

[...] o mais importante instrumento jurídico positivo brasileiro para efetivação dos direitos humanos das mulheres de possuir uma vida livre de violências [...] demonstrou-se que há uma grande defasagem entre a norma e a realidade; entre o reconhecimento positivo (enunciação legal) e o alcance das condições reais para efetivação do direito humano [...] (TÁBOAS, 2014, p. 99).

Nessa perspectiva, o grande desafio, de fato, está em possibilitar as condições objetivas para que a LMP se efetive. Em outras palavras, mais do que avanços formaisnormativos, faz-se necessário transformações concretas para superação do Estado patriarcal-racista-capitalista, que determina relações que provocam um continum de violência contra as mulheres.

\section{Conclusão}

A luta contra todas as formas de violência à mulher encontra um inimigo comum: o patriarcado. Isso demanda com o reconhecimento e investimento por parte do Estado em todas as políticas públicas, tanto para atuar na prevenção e no enfrentamento às violências, como para possibilitar o devido atendimento, acolhimento e orientação às vítimas, por meio de uma Rede Especializada composta por Centro de Referência psicossocial e jurídico, Casa Abrigo e Juizados Especiais, 
como preconiza a Lei Maria da Penha. Os hospitais públicos e outras unidades de saúde também são instituições importantes para o enfrentamento à violência, pois, muitas vezes, são a porta de entrada para o acolhimento da mulher vitimizada. Daí a importância da notificação e o encaminhamento da mulher para o Centro de Referência psicossocial e jurídico. Essa porta de entrada, pode, no entanto, não ser em uma instituição de saúde, por vezes, ocorre nos Centros de Referência em Assistência Social (CRAS) e nos Centros de Referência Especial em Assistência Social (CREAS), por exemplo.

Compreende-se, portanto, que o fenômeno da violência pode demandar respostas de qualquer instituição, por isso, a necessidade de entender sobre esse tema, bem como a legislação que o envolve, com destaque para a Lei Maria da Penha.

A aprovação da LMP representou, sem dúvida, um significativo avanço legislativo desde a Constituinte de 1988. O que antes era considerado um problema de esfera privada, torna-se agora, pública. Uma lei, todavia, por mais avanços que possa possibilitar do ponto de vista jurídico-normativo, é determinada em seus limites e possibilidades pelas relações sociais que envolve. Tais relações são estruturalmente definidas pelos marcadores de sexo, raça e classe do sistema patriarcal-racistacapitalista no qual se vive.

A Lei, logo que sancionada, provocou grande resistência por parte do poder judiciário-patriarcal, inclusive, acusando-a de inconstitucional o que, felizmente, não logrou êxito. Isso demonstra como o direito patriarcal, "que institui o poder dos homens sobre as mulheres nas sociedades modernas ocidentais, viu-se fortemente ameaçado por esta lei" (AMB, 2011, p. 48).

Esse direito patriarcal está presente nas estruturas do Estado, pela falta de atenção, descaso ou mesmo culpabilização da vítima, provocando a "sobrevitimização" ou "vitimização secundária". Esse processo é intensificado em relação ao pertencimento étnico-racial e de classe das mulheres vitimizadas. Assim, há um dano adicional causado às mesmas, ocasionado pela própria justiça penal formal. Há também, nesse processo, a morosidade na implementação das varas especializadas, um mecanismo indispensável para efetivar os inquéritos e os processos.

Dessa forma, incidir sobre uma forte estrutura burocrática, historicamente patriarcal-racista e elitista, associada aos parcos recursos destinados às políticas de 
combate à violência contra a mulher, não é um contexto favorável à efetivação da LMP. A rede de serviços que a LMP prevê, embora hoje, seja significativamente maior, ainda é bastante insuficiente e precária, concentrando-se mais nas capitais e grandes cidades.

Além da rede de equipamentos diretamente ligada à questão da violência contra a mulher, ressalta-se a importância do investimento público na prevenção da violência por meio de uma educação não sexista nas escolas. O enfrentamento desse tema precisa estar presente em todas as profissões e políticas sociais, bem como por meio do compromisso dos movimentos sociais e partidos políticos de esquerda.

Apesar de todas essas dificuldades para a efetivação das medidas e ações previstas pela LMP, ainda é um documento legislativo à frente das leis dos principais países da América Latina, ao trazer por exemplo, em seu artigo $5^{\circ}$ inciso II, que a 0 âmbito família compreende "a comunidade formada por indivíduos que são ou se consideram aparentados, unidos por laços naturais, por afinidade ou por vontade expressa"16, abrangendo assim, qualquer tipo de vínculo por afinidade que exista entre a mulher e seu/sua agressor(a), bem como ao tratar que a violência pode se dar em qualquer relação íntima de afeto, independente de coabitação.

Essa grande importância normativa, todavia, precisa ganhar materialidade. Para tanto, fortalecer as lutas contra um sistema marcadamente patriarcal, racista e capitalista, parecendo o único caminho. Nesse sentido, ressaltou-se a importância da construção de um projeto societário sintonizado com a perspectiva feminista, antirracista e socialista, para que assim, possa ser superado todas as explorações, opressões e violências históricas que marcam a vida das mulheres, especialmente as racializadas.

\section{Referências}

ALEMANY, C. Violências. In: HIRATA, H. et al. (Org.). Dicionário crítico do feminismo. São Paulo: Ed. UNESP, 2009.

AMB. Políticas Públicas para a Igualdade: balanço de 2003 a 2010 e desafios do presente. Brasília: CFEMEA, 2011.

16 BRASIL. Lei $\mathrm{n}^{\circ}$ 11.340, de 7 de agosto de 2006. http://www.planalto.gov.br/ccivil 03/ ato20042006/2006/lei/l11340.htm. Acesso em: 29 de outubro de 2017. 
BANDEIRA, L. Três décadas de resistência feminista contra o sexismo e a violência feminina no Brasil: 1976 a 2006. Sociedade e Estado, Brasília, v. 24, n. 2, p. 401-438, maio/ago. 2009.

BARROS, F. M. A participação da vítima no processo penal. Rio de Janeiro: Lumen Juris, 2008.

BARROSO, M. F. Rotas críticas das mulheres Sateré-Mawé no enfrentamento à violência doméstica: novos marcadores de gênero no contexto indígena. Manaus: EDUA, 2015.

BRASIL. Decreto $n^{\circ} 1.973$ de $1^{\circ}$ de Agosto de 1996. Brasília.

BRASIL. Lei $n^{\circ}$ 11.340, de 7 de agosto de 2006. Brasília.

CARVALHO, A. B. Teoria e prática do direito alternativo. Porto Alegre: Síntese, 1998.

COUTINHO, J. N. M. "Segurança Pública e o Direito das Vítima". In: CARVALHO, S. et al. (Org.). Direitos humanos e globalização: fundamentos e possibilidades desde a teoria crítica. 2. ed. Porto Alegre: EDIPUCRS, 2010.

CFEMEA. CENTRO FEMINISTA DE ESTUDOS E ASSESSORIA. ANÁLISE DAS ELEIÇÕES. Mulheres eleitas em 2014: velhos e novos desafios. Brasília: CFEMEA, 2014.

CHAUÍ, M. Brasil. Mito fundador e sociedade autoritária. São Paulo: Perseu Abramo, 2007.

GARCIA, L. P.; FREITAS, L. R. S.; SILVA, G. D. M.; HÖFELMANN, D A. Violência contra a mulher: feminicídios no Brasil. Disponível em: <http://horia.com.br/sites/default/files/ documentos/130925_sum_estudo_feminicidio_leilagarcia.pdf $>$. Acesso em: $8 \mathrm{mar}$ 2015.

GUILLAUMIN, C. Enquanto tivermos mulheres para nos darem filhos: a respeito da raça e do sexo. Estudos Feministas, v. 2, jul./dez. 1994

Prática do poder e a ideia de natureza. In: FERREIRA et al. (Org.). $O$

Patriarcado Desvendado: teorias de três feministas materialistas. Recife: SOS CORPO, 2014.

LÔBO, P. Do poder familiar. In: DIAS, M. B.; PEREIRA, R. C. (Coord.). Direito de família e o novo Código Civil. 3. ed. Belo Horiznte: Del Rey, 2003

OLIVEIRA, A. S. S. A vítima e o direito penal. São Paulo: Revista dos Tribunais, 1999.

SAFFIOTI, H. Gênero, patriarcado, violência. São Paulo: Perseu Abramo, 2004.

. Violência de Gênero: poder e impotência. Rio de Janeiro: Revinter, 1995.

TÁBOAS, Í. D. M. Z. Viver sem violência doméstica e familiar: a práxis feminista do Movimento de Mulheres Camponesas. Dissertação de mestrado. 2014. Dissertação 
(Mestrado em Direitos Humanos e Cidadania do Centro de Estudos Avançados Multidisciplinares) - Universidade de Brasília, Brasília, 2014.

WAISELISZ, J. J. Mapa da Violência 2015: homicídios de mulheres no Brasil. Brasília-DF, 2015.

Recebido em: 13/11/2017

Aceito em: 20/01/2018 